\title{
RESIDENTIAL COMMUNITY MICRO GRID LOAD SCHEDULING AND MANAGEMENT SYSTEM USING COOPERATIVE GAME THEORY
}

Sania Khaskheli

Master's Student, Electronic System Engineering, Institute of Information and Communication Technologies, Mehran UET. Jamshoro (Pakistan) E-mail: sania.14es.01.muet@gmail.com

Irfan Ahmed Halepoto

Department of Electronic Engineering, Mehran UET. Jamshoro (Pakistan) E-mail: irfan.halepoto@gmail.com

Ayesha Khalid

Master's Student, Information Technology, Institute of Information and Communication Technologies, Mehran UET. Jamshoro (Pakistan) E-mail: ayesha87khalid@gmail.com

Recepción: 05/03/2019 Aceptación: 15/03/2019 Publicación: 17/05/2019

Gitación sugerida:

Khaskheli, S., Halepoto, I. A. y Khalid, A. (2019). Residential Community Micro Grid Load Scheduling and Management System Using Cooperative Game Theory. 3C Tecnología. Glosas de innovación aplicadas a la pyme. Edición Especial, Mayo 2019, pp. 534-551. doi: http://dx.doi.org/10.17993/3ctecno.2019.specialissue2.534-551

Suggested citation:

Khaskheli, S., Halepoto, I. A. \& Khalid, A. (2019). Residential Community Micro Grid Load Scheduling and Management System Using Cooperative Game Theory. 3C Tecnología. Glosas de innovación aplicadas a la pyme. Special Issue, May 2019, pp. 534-551. doi: http://dx.doi.org/10.17993/3ctecno.2019.specialissue2.534-551 


\section{ABSTRACT}

This paper proposes a residential community based microgrid using cooperative game theory to share excessive energy within a community's neighbor homes for optimal load scheduling and management. The proposed model is a grid connected residential community where smart homes are connected through central energy management system (EMS) to share the benefits of excessive distributed energy resources (DERs) from solar PV or wind turbine by selling to other community residents at a price lower than the utility gird but higher than the feed-in tariff. The community smart homes are categorized as Externally Importing Homes, Internally Exporting Homes and Externally Exporting Homes which are further classified as passive consumers, active prosumers and proactive prosumers based on the facilities they possess in form of DERs and battery storage (BS). With the cooperative energy transaction mechanism, the smart community homes after fulfilling their own load requirements can place the excessive energy on community poll using decentralized or centralized approach through peer to peer trading or smart community manager (SCM) respectively. The excessive energy can be sold or purchased to and from other community homes as per some defined preferences and priorities. This will benefit the entire community in terms of cost compared to the utility grid's Time of Use (ToU) pricing. Proposed system will not only share, schedule and manage the community load optimally but will reduce the overall energy cost, system operational stress, improves system operational efficiency and reduces carbon emission.

\section{KEYWORDS}

Residential Microgrid, Distributed Energy Resources, Cooperative Game Theory, Load Scheduling, Energy Management System. 


\section{INTRODUCTION}

Considering the scarcity of conventional energy sources, increasing environmental carbon emission and requirement of improved operational efficiency needs diverse, and smarter solutions for meeting energy efficiency and conservations at the same time (Halepoto, Uqaili, \& Chowdhry, 2014). Residential sector contributes almost one third share of energy consumption (Sahito, et al., 2015) and unfortunately this sector mostly relies on conventional energy sources. There is a strong need to shift the residential load by utilizing small DERs to minimize the concerns about polluted carbon emission and to meet the ever-growing energy requirements and operational stability (Basu, Chowdhury, Chowdhury \& Paul, 2011). Recently, the electric power industry has seen the acceleration in DERs installation and utilization. Microgrids are the most complex and dynamic form of DERs. A microgrid is setup by integrating the interconnected electric loads and DERs acting as a single controllable entity with respect to the grid (Planas, Gil-de-Muro, Andreu, Kortabarria \& de Alegría, 2013). In recent years, microgrids have evolved from a growing concept to a significant source of opportunity however it is still in the developing phase as there isn't one--size-fitsin all microgrid development system. In the microgrid industry, the immense focus has been given to the institutional campus, commercial or industrial segments, but now there is a growing trend to expand these applications to serve broader needs. Residential communities can serve this purpose as it is broadly accepted that the electric utility future is only sustainable and reliable with resilient communities to supplement the existing energy infrastructure with microgrids.

Since DERs are internment in nature and their availability is subject to natural concerns and climatically variations, these resources must be operated in a coordinated manner. For the interactive operation of DER in a coordinated approach, the introduction of multi-agent system (MAS) can provide hierarchical control architecture for the optimization of resources and to avoid any operational uncertainty (Halepoto, Sahito, Uqaili, Chowdhry \& Riaz, 2015). This can framework an efficient load sharing, load scheduling and EMS especially for residential sector by developing a community based residential 
microgrid where each resident is cooperative with each other in game theory concept. In a game theory, instead of each user utilizing the DERs individually for its own load usage and management, a better approach can be to use DERs as cooperative load management scheme (Parisio, Wiezorek, Kyntäjä, Elo, Strunz $\&$ Johansson, 2017). The community microgrid can potentially serve the needs of both community residents and utility grids by selling or purchasing the excess amount of energy optimally, as every residential community home consumer can be a prosumer (producer and consumer) at the same time.

The reminder of paper is organized as follows. In section 2 a residential smart home system model is proposed and discussed being the mandatory requirement of community microgrid. A residential smart home community based microgrid developed in Section 3 which categorizes three types of community homes on base of facilities they possess. In Section 4 a cooperative game theory based energy management system for community microgrid is proposed using EMS. A prosumer-centric residential community microgrid system using decentralized and centralized design is proposed and analyzed in Section 5. Section 6 concludes the work and point to the future work directions.

\section{RESIDENTIAL SMART HOME SYSTEM MODEL}

The residential community microgrid is strongly dependent on residential smart home system (RSH) as proposed in Figure 1. The smart homes are utility grid connected and are equipped with RESs (PV solar system, and wind turbine), solar charge controller, wind charge controller; advance metering infrastructure (AMI) based smart meter, energy scheduling unit (ESU), energy management controller (EMC), DC/AC inverters, battery storage (BS) and home appliances. Through smart meter, not only the bi-directional communication between utility grid and consumers can be established but the consumer can get real time information about load demand, energy consumption data and electricity prices especially ToU pricing. The solar PV system generates the electricity in DC form which is then converted into AC form via DC/AC converter. The BS is utilized for both 
source and sink purpose to store DERs produced energy. The ESU is responsible to generate and schedule the appliance energy consumption data and send the scheduling patterns to the EMC. According to the generated schedules by ESU, the EMC controls the BS and appliance's operation.

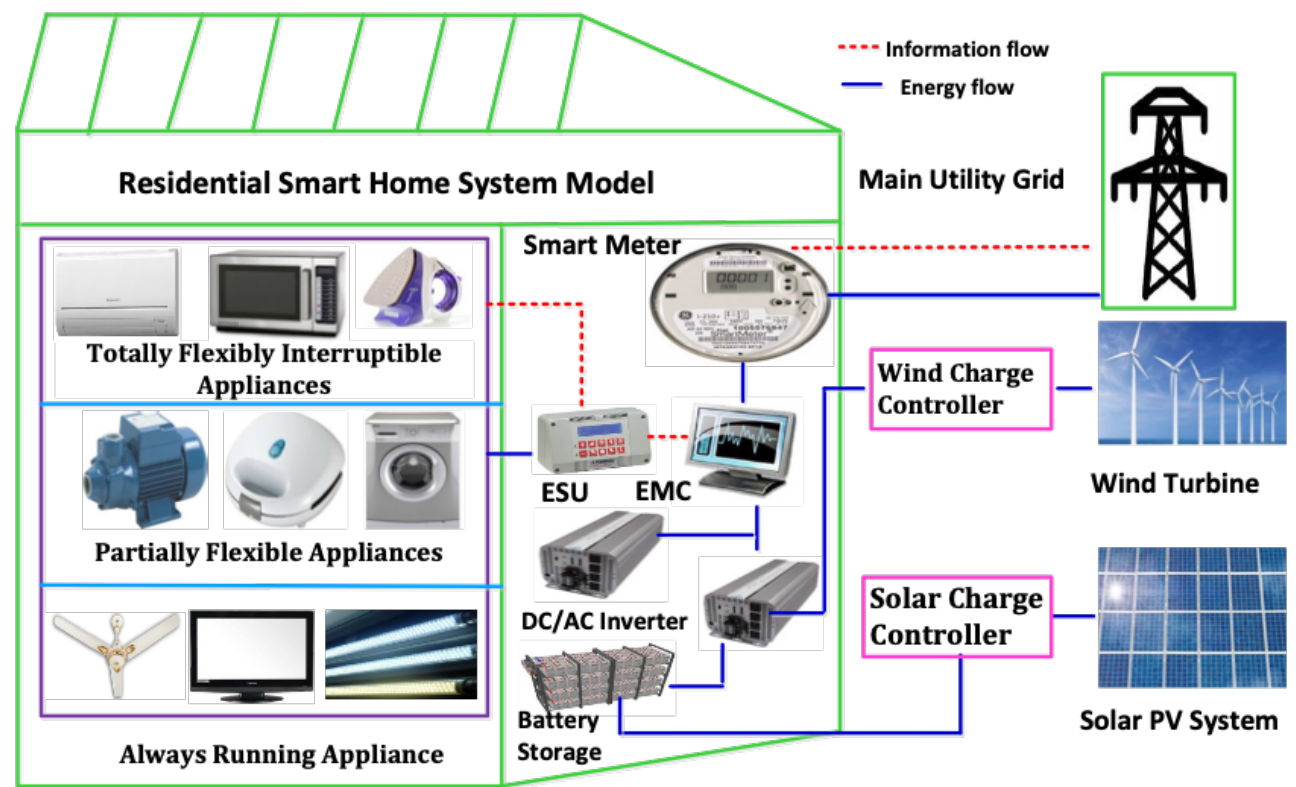

Figure 1. Residential Smart Home System Model.

The home appliances are categorized into three types by end consumers according to schedulability, flexibility and interruptibility; (i) Partially Flexible Appliances (PFA), (ii) Totally Flexibly Interruptible Appliances (TFA), (iii) Always Running Appliances (ARA). With PFA, the consumers are partially flexible to shift or schedule the appliances load to another time slots. The starting and finishing time slots are defined already with mostly one hour time interval. Once any appliance is started, it will complete the one hour operating time slot; after that, the consumer will follow the utility request to schedule or curtail the load for next time slot. With TFA, as per defined agreement between the utility and consumers, the end consumer must cutoff, curtail or schedule the electric load as per utility request at any time. The ARA is most inflexible type as the consumer's home appliances are not non-interruptible, non-deferrable and non-shiftable. These types of appliance are always run type of appliances. 


\section{RESIDENTIAL COMMUNITY HOMES BASED MICROGRID}

This paper aims to model a residential community based microgrid to generate, utilize and serve multiple residential home prosumers in cooperate way to share or sell excessive DERs energy to the other community residents or even to main grid at a price lower than the utility gird's price but higher than the feed-in tariff. The community homes are grid connected and are classified into three types; Externally Importing Homes, Internally Exporting Homes and Externally Exporting Homes . The considered model homes and their parameters are shown in Figure 2.

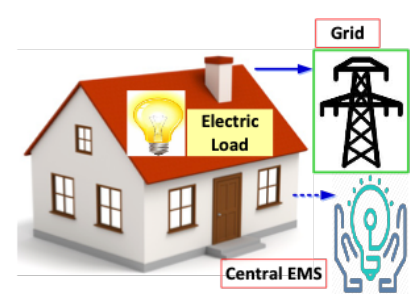

(a) Externally Importing Home

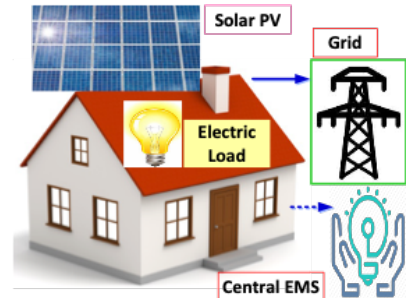

(b) Internally Exporting Home

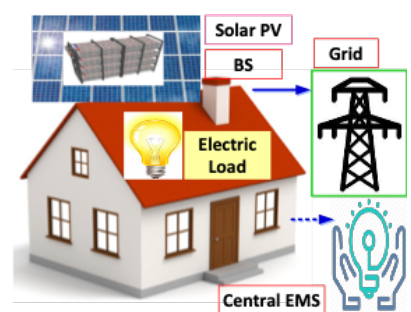

(c) Externally Exporting Home

Figure 2. The different types of homes in a community microgrid.

Externally Importing Homes: The residents of does not possess any DERs (either cannot afford DERs or not willing to install) and are totally dependent to utility grid supply and on community homes which one offers low electricity prices. Such residents are a greedy and passive consumer whose only focus is low electricity prices, even not on the energy availability.

Internally Exporting Homes: The residents of are active prosumers. They have DERs installed to meet their energy demands but they do not possess any battery storage. After meeting their energy demands, the owners become part of residential community through a SCM to sell excessive energy to their neighbor homes especially to external importing homes on priority. In case, the neighboring homes do not require energy at that time since these homes do not have any backup battery system, they try to sell energy to the grid rather than wasting it. 
Externally Exporting Homes: The residents of are proactive prosumers. These are ideal community homes possessing both the DERs and BS. Such homes after filling their own energy requirements store the additionally available energy through BS. After that, they try to share or sell the excessive energy to the neighbors especially to through the smart community manager.

As externally importing homes are without DERs so they always need energy either to be purchased from the utility grid or from other community homes, depending which one is offering lowest prices. The offered price from utility will base on ToU price, so for case of high peak price periods, they can purchase energy form community homes through SCM using cooperative game theory. Being the part of community microgrid, they may get the energy at a price lower than the utility gird price but still higher than the feed-in tariff. On the other hand, the internally exporting homes will put their excessive energy into community poll for sell through the SCM at a very low feed-in tariff during the day. Since such homes do not have BS, so during nights they may also need to purchase the energy either from externally exporting homes or from the utility grids depending on the ToU pricing periods. As a special case, since externally exporting homes have both DERs and BS, so they can easily store the energy which can be utilized during nights. Even with storage, if they sell out the stored energy to community homes at some earlier time of the day, they may also face power shortage during night's occasionally.

\section{COOPERATIVE GAME THEORY BASED ENERGY MANAGEMENT SYSTEM}

Game theory is a multi-agent based concept where different autonomous rational players interact with each other for mutual benefits (Nguyen, Kling \& Ribeiro, 2013). This game theory concept can be very effective to energy related applications especially in community based micro grids for optimizing the energy resources (Mei, Chen, Wang \& Kirtley, 2019). The game theory is classified into cooperative and non-cooperative game theory (Stevanoni, Grève, Vallée \& 
Deblecker, 2019). In non-cooperative game theory, different players which are the part of the system, partially interact with each other to achieve their own individual objective(s) which can be contradictory to overall system objectives. On the other hand, cooperative game theory is based on a coalitional game theory, where all the set of players are always ready to cooperate, coordinate and communicate with each other without any conflict of interests to achieve one common goal. Figure 3 illustrate the community based microgrid configuration connectivity of different homes using EMS.

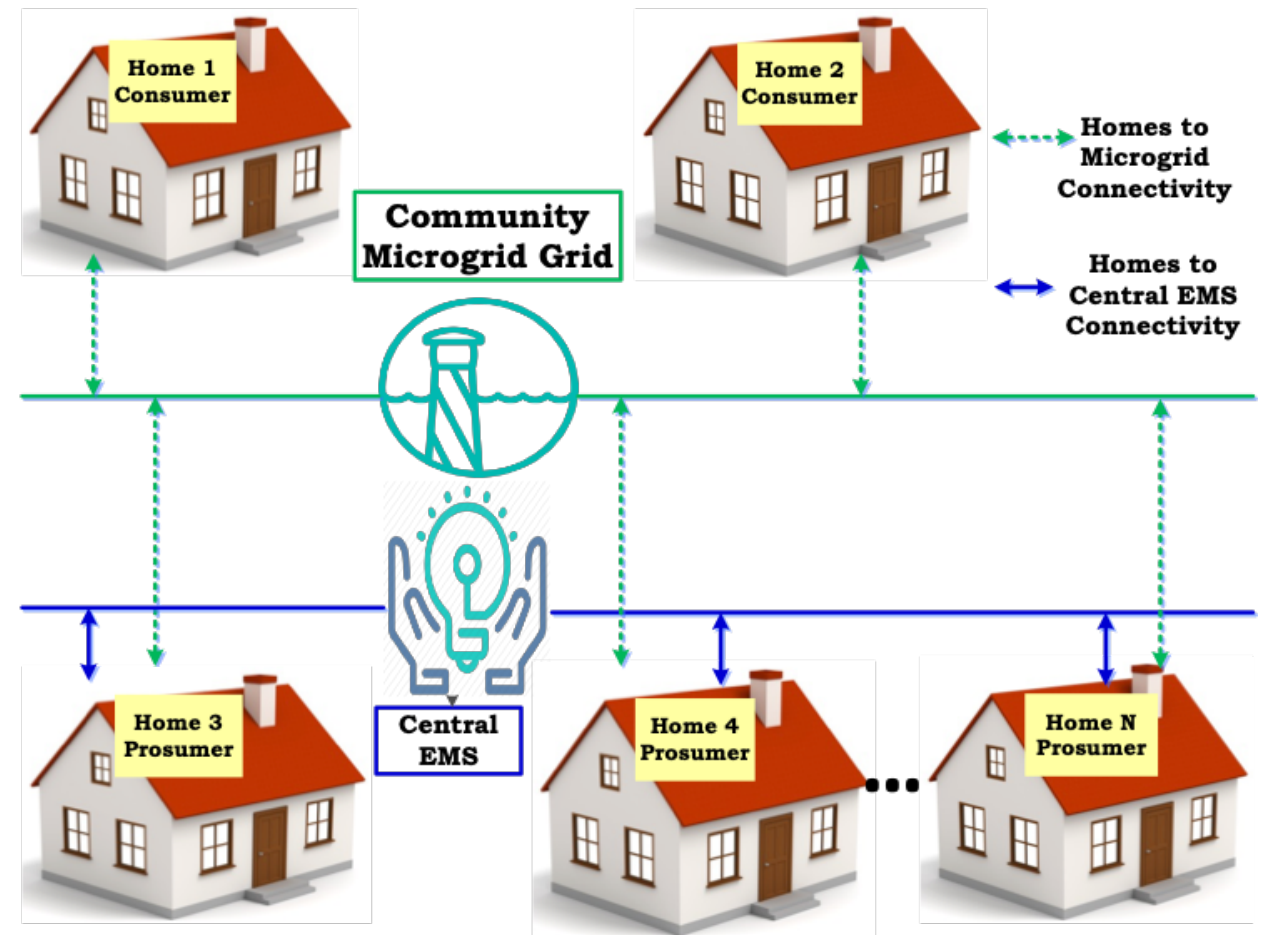

Figure 3. Residential Community Microgrid Connectivity Configuration using central EMS.

The prime objective of cooperative game in a community microgrid is to schedule and optimize the electricity load requirements within the community smart homes. Being the prosumer, the locally generated electricity from DERs is used by homes to fill their load demands and after meeting the requirements the excess energy is either sold back to the community resident or to utility grid. Although this is an attractive solution for both utility and community prosumers, this can be more effective if managed optimally through community microgrid 
manager using MAS to develop the communication at different layers. Figure 4 shows the MAS configuration for a central EMS which comprises of three communication levels; primary, secondary, and tertiary EMS.

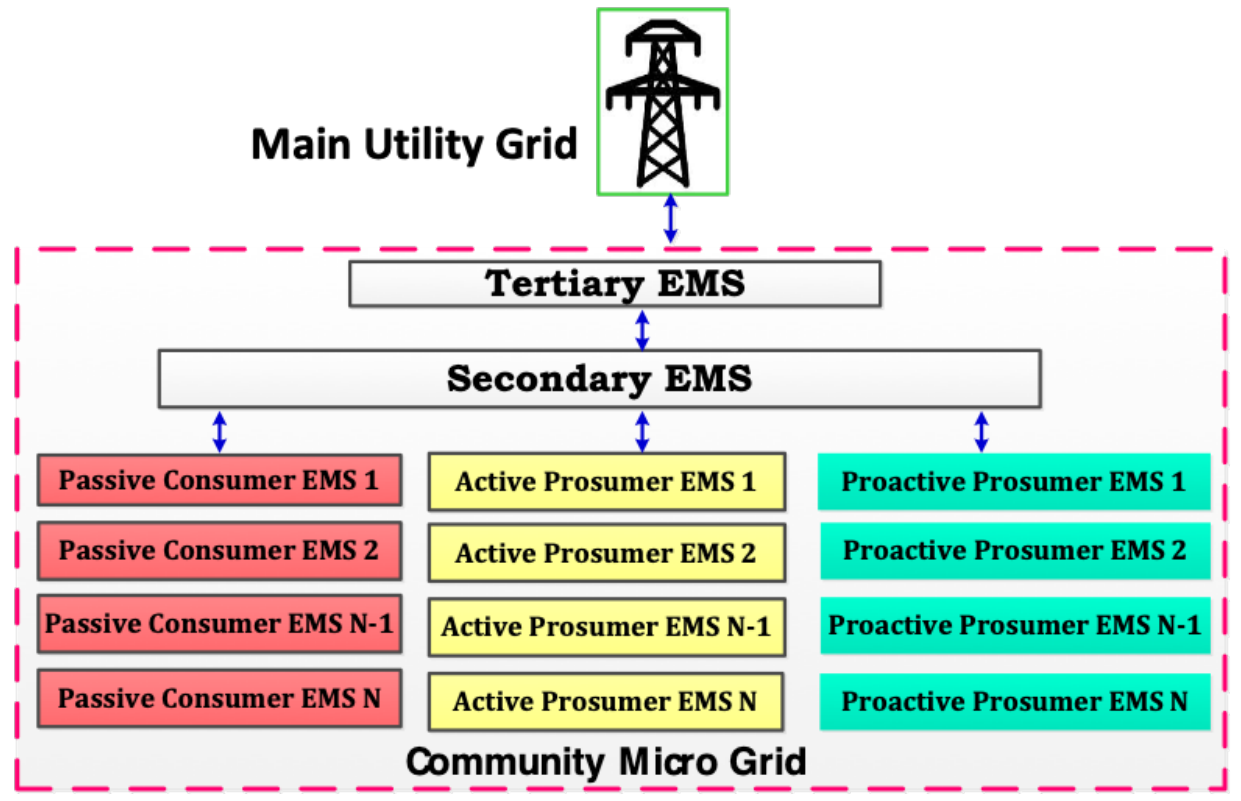

Figure 4. MAS Configuration for a central EMS in Community Microgrid.

The community smart homes are considered as the primary EMSs. At the primary level, every smart community home having its own EMS, communicates its ongoing energy status with the secondary EMS, which on receiving the information shares the energy status and places an excess amount of energy on community poll for other community homes less than the utility grid's prices according to priorities defined by community homes for sell or purchase. Finally, the tertiary EMS being the overall decision maker, based on secondary EMS information, accumulates the overall energy status and decide(s) for buying or selling energy to and from the utility grid. 


\section{PROPOSED PROSUMER-CENTRIC RESIDENTIAL COMMUNITY MICROGRID}

In this paper, we have proposed two stage prosumer--centric residential cooperative community microgrid; decentralized cooperative community microgrid design and centralized cooperative community microgrid design. We have molded six community homes, two from each category being passive consumer, active prosumer and proactive prosumers.

Decentralized Cooperative Community Microgrid Design: This is a decentralized or distributed agent based design approach where the community homes' residents can directly negotiate with each other in form of grouping or peer to peer $(\mathrm{P} 2 \mathrm{P})$ to make energy transactions (selling or purchasing) without involving any centralized supervisory mechanism like smart community manager, as shown in Figure 5.

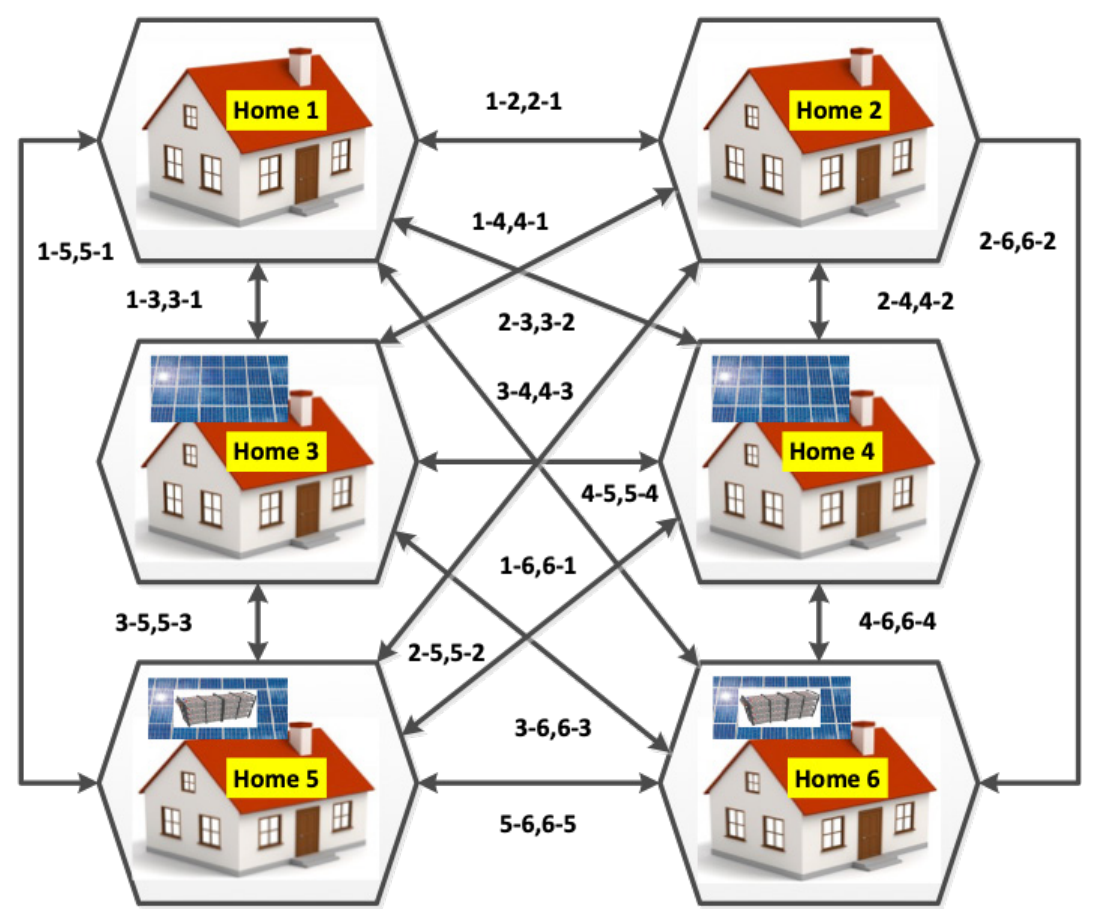

Figure 5. Decentralized Cooperative Community Microgrid Design. 
Figure 5 illustrates all the possible combination of $\mathrm{P} 2 \mathrm{P}$ trading patterns between all community homes. The trading patterns are shown vice versa form where everyone can trade (sell or purchase) with other one. The information is only shared to those community homes that are willing to trade the energy (sell or purchase) in $\mathrm{P} 2 \mathrm{P}$ form. The price of energy transaction is kept in secrecy. Figure 6 illustrates the model example microgrid consisting of 6 community homes trading in P2P. The peers 1 and 2 are passive consumers; peers 3 and 4 are active prosumers while peers 5 and 6 are proactive prosumers. For the illustration purpose we have chosen prosumer 3 is one community home which has some excessive amount of energy. Since it equipped only with DERs but does not possess ant battery back, so he desperately wants to sell the excessive energy. Since this is a decentralized approach so community home by itself tries to find out the target homes. This example illustration of prosumer 3 is shown in Figure 6. Consumers have prosumers as energy transaction trading partners and while prosumers have both consumers and producers as trading partners. Considering the negotiation process, the pricing priorities for bilateral trade can be defined and may vary accordingly for trade between the peers. Considering the prosumer 3 case scenario, the bilateral trading between four prosumers can be made by using reciprocity property as shown in Figure 6 .

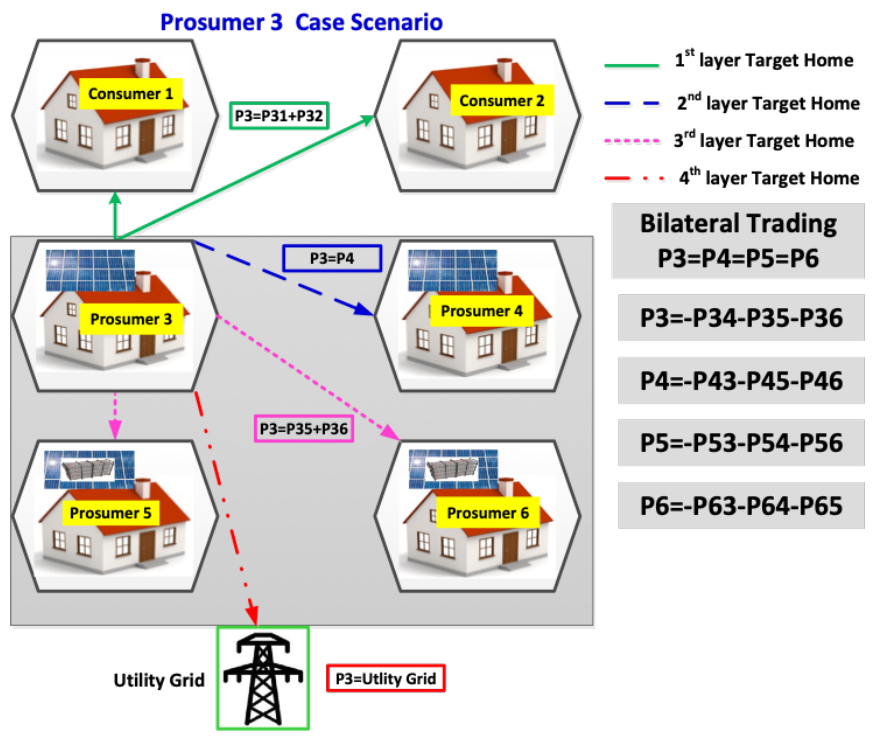

Figure 6. Decentralized Cooperative Community Microgrid Design Trading in Peer to Peer. 
This confirms that all four prosumers have equal opportunities of balance trade during bilateral trading but with opposite sign. This design is truly a consumers' preference centric where the owner has total freedom to whom energy transaction is to be made. At the same time the negotiation process (price, time horizon) scalability and limitations are the main issues. The negotiation process can become more complex for the scenarios where a greater number of community homes are involved, as both the seller and the buyer are unaware about the requirements and priorities of each other.

\section{Centralized Gooperative Community Microgrid Design:}

This is centralized poll based design approach where all community homes put their excessive energy on the community energy poll and is managed, decided and shared through a CSM which acts as an intermediator between all the community homes. This system design is shown in Figure 7. Based on three community homes categories; a centralized cooperation through SCM can be made based on different priorities or preferences mainly on electricity prices and available time horizon defined by community homes owners. Based on defined priorities, the SCM is responsible to decide to whom the excess energy is to be sold to or purchased from on the bases of auction schemes where the energy seller's and buyer's demands are met. It is not necessary for the seller and the buyer to know each other as energy transactions are handled through the SCM. This design is more structured and optimized where most of the community members can not only be in a social relationship by helping other community residents but can also earn good revenues as energy can also be sold to utility grid at higher prices when the utility grid is under system stress through smart community manager. This scenario can be more realistic if through SCM an aggregated energy is sold to the utility grid and total collected revenue is shared (e.g., in a logical proportional way) midst all community members. At the same time, SCM has the strong responsibility of being fair and unbiased so that every community home gets equal opportunities of energy transaction. 


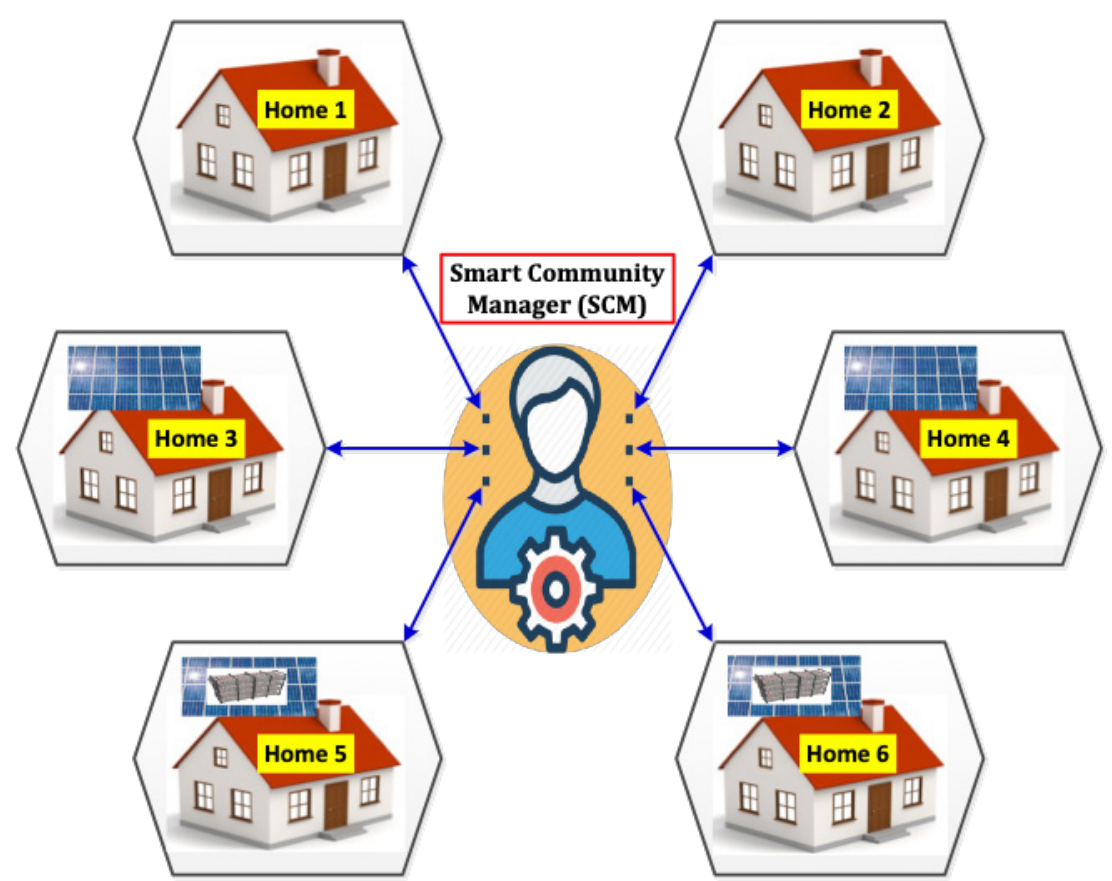

Figure 7. Centralized Cooperative Community Microgrid Design through Smart Community Manager.

\section{CONCLUSION}

In this paper, a grid connected residential community based microgrid is proposed using cooperative game theory to share, manage and schedule the excessive amount of energy generated through DERs with the community neighboring homes. In this work, three types of community home residents' passive consumers, active prosumers and proactive prosumers are used as the main agents which makes the energy trading and transaction to other community residents after fulfilling their own load requirements. This energy trading and transaction is based on two stage prosumer-centric residential cooperative approach in centralized or decentralized way to sell or purchase the energy from community neighboring homes at a price lower than the utility gird but higher than the feed-in tariff. With decentralized approach community residents can directly negotiate with each other in form of grouping $\mathrm{P} 2 \mathrm{P}$ to make energy transactions; whereas in centralized approach all community homes put their excessive energy on the community energy poll and is managed, decided and shared through a smart 
community manager which acts as an intermediator between all the community homes. It is concluded that the proposed system will not only share, schedule and manage the community load optimally but reduces the overall energy cost, system operational stress, improves the system operational efficiency and reduces the carbon emission. This work can be extended further to develop the rural electrification using community microgrid especially in energy deficit countries like Pakistan to avoid grid system stress.

\section{ACKNOWLEDGMENTS}

Authors are highly grateful to Mehran University of Engineering and Technology, Jamshoro, Pakistan, for the necessary support, technical laboratory facilities and comfortable research environment. 


\section{REFERENCES}

Basu, A. K., Chowdhury, S. P., Chowdhury, S. \& Paul, S. (2011). Microgrids: Energy management by strategic deployment of DERs - A comprehensive survey. Renewable and Sustainable Energy Reviews, 15(9), pp. 4348-4356. doi: http://dx.doi.org/10.1016/j.rser.201 1.07.116

Halepoto, I. A., Sahito, A. A., Uqaili, M. A., Chowdhry, B. S. \& Riaz, T. (2015). Multi-criteria assessment of smart city transformation based on SWOT analysis. In IEEE $5^{\text {th }}$ National Symposium on Information Technology: Towards New Smart World, pp. 1-6. doi: http://dx.doi.org/10.1109/ NSITNSW.2015.7176412

Halepoto, I. A., Uqaili, M. A. \& Chowdhry, B. S. (2014). Least square regression based integrated multi-parametric demand modeling for short term load forecasting. Mehran University Research Fournal of Engineering and Technology, 33(2), pp. 215-226.

Mei, J., Chen, G., Wang, J. \& Kirtley, J. L. (2019). Coalitional game theory based local power exchange algorithm for networked microgrids. Applied Energy, 239(C), pp. 133-141. doi: http://dx.doi.org/10.1016/j. apenergy.2019.01.208

Nguyen, P. H., Kling, W. L. \& Ribeiro, P. F. (2013). A game theory strategy to integrate distributed agent-based functions in smart grids. IEEE Transactions on Smart Grid, 4(1), pp. 568-576. doi: http://dx.doi.org/10.1109/ TSG.2012.2236657

Parisio, A., Wiezorek, G., Kyntäjä, T., Elo, J., Strunz, K. \& Johansson, K. H. (2017). Cooperative MPC-based energy management for networked microgrids. IEEE Transactions on Smart Grid, 8(6), pp. 3066-3074. doi: http:// dx.doi.org/10.1109/TSG.2017.2726941

Planas, E., Gil-de-Muro, A., Andreu, J., Kortabarria, I. \& de Alegría, I. M. (2013). General aspects, hierarchical controls and droop methods in microgrids: A review. Renewable and Sustainable Energy Reviews, 17, pp. 147-159. 
Sahito, A. A., Halepoto, I. A., Uqaili, M. A., Memon, Z. A., Larik, A. S. \& Mahar, M. A. (2015). Analyzing the impacts of distributed generation integration on distribution network: A corridor towards smart grid implementation in Pakistan. Wireless Personal Communications, 85(2), pp. 545563. doi: http://dx.doi.org/10.1007/s11277-015-2754-y

Stevanoni, G., De Grève, Z., Vallée, F. \& Deblecker, O. (2019). Longterm planning of connected industrial microgrids: A game theoretical approach including daily peer-to-microgrid exchanges. IEEE Transactions on Smart Grid, 10(2), pp. 2245-2256. doi: http://dx.doi.org/10.1109/ TSG.2018.2793311 
Edición Especial Special Issue Mayo 2019

DOI: http://dx.doi.org/10.17993/3ctecno.2019.specialissue2.534-551 